\title{
As possibilidades da inclusão do aluno surdo no curso de Ciências Biológicas
}

\author{
Tatiane Aparecida Silva* \\ Luiz Antonio Silva** \\ Vanessa Suzuki Kataguiri*** \\ Deicy Lorrane Rodrigues Araujo ${ }^{* * * *}$
}

\section{Resumo}

As dificuldades ou limitaçóes na educação dos surdos sempre foram motivos de inquietaçôes, principalmente quando se trata de incluir estes alunos no espaço acadêmico. A falta de conhecimento sobre as diferenças que separam ouvintes e surdos ainda é um tabu para as pessoas que não participam de sua cultura ou forma de comunicaçáo. Pensando neste momento de interação é que esta pesquisa objetivou avaliar as condiçóes e as necessidades de um aluno surdo durante as aulas teóricas e práticas do Curso de Ciências Biológicas UFU-FACIP. Participaram da pesquisa setenta e cinco discentes, dez docentes e quatro técnicos do Curso de Ciências Biológicas UFU- FACIP e cursos associados. Os resultados da pesquisa apontam aspectos importantes sobre o pouco conhecimento e convivência dos discentes, docentes e técnicos em relação aos surdos, o que torna essa interação uma novidade na Universidade. Concluindo assim que estes apresentaram grandes dificuldades para descrever o impacto da interação com um aluno surdo em sala de aula.

Palavras-chave: Ciências Biológicas; Educação Especial; Surdo.

\footnotetext{
* Graduada em Ciências Biológicas pela Universidade Federal de Uberlândia, Uberlândia, Minas Gerais, Brasil.

** Especialização em andamento em Tecnologias Aplicadas ao Ensino de Biologia pela Universidade Federal de Goiás, Goiânia, Goiás, Brasil.

*** Professora da Universidade Federal de Uberlândia, Ituiutaba, Minas Gerais, Brasil.

**** Graduada em Ciências Biológicas pela Universidade Federal de Uberlândia, Uberlándia, Minas Gerais, Brasil.
} 


\section{The possibilities of including deaf students in the biological sciences course}

\section{Abstract}

Concerns have always been raised about the difficulties and limitation found in deaf education, mainly when it comes to including these students in academic space. The lack of knowledge about the differences between deaf and hearing people is still a taboo for those who do not take part in their culture and way of communicating. Taking into consideration the interactions among them, this research aimed to analyze the deaf students' conditions and needs in theoretical and practical classes in the Biological Sciences Course in UFU - FACIP. Seventy-five students, ten professors and four technicians from the Biological Sciences Course in UFU - FACIP and associated courses took part in this research. The results of this research bring up some important aspects about the students, professors and technicians' unawareness about the Deaf, characterizing this sort of interaction as something new in the University. For that reason, they face considerable difficulties in describing the impact of this interaction with deaf students in the classroom.

Keywords: Biological Sciences; Inclusive Education; Deaf.

\section{Introdução}

A inclusão de pessoas surdas, nos últimos anos, tem ocupado grande espaço nas discussóes sobre o direito de acesso deste grupo minoritário à universidade. Uma das dificuldades no processo de permanência e sucesso do surdo, no ensino superior do Brasil, reflete sobre duas questôes, a de universalização e de democratização (MIRANDA; SILVA, 2008), que estâo garantidas nas leis do país, de direito à educação, saúde e moradia, conforme a Lei n. 9. 394/96 no Art. 58 a 60 da Lei de Diretrizes e Bases da Educação Nacional que preconiza o "atendimento aos portadores de necessidades especiais, preferencialmente na rede regular (inclusão), assim como a adaptação da escola e do currículo e a integraçáo na vida em sociedade" (BRASIL, 1996).

Outra questão que interfere na permanência dos alunos com deficiência no Ensino Superior é a carência de profissionais preocupados e/ou envolvidos com pesquisas e projetos na área da educação especial e na inclusão de alunos com deficiência. As universidades precisam assumir também o papel de pesquisar temas relacionados às dificuldades de aprendizagem do surdo e seu enfretamento (GRASSI, 2009), somente assim, parte do problema poderá ser resolvido.

Os surdos foram privados de serem educados até o século XV, mas a partir do século XVI, apareceram os primeiros educadores de surdos, entre eles, Ponce de León (1520-1584), um monge beneditino da Espanha, que dedicou a maior parte da sua vida para educar os surdos, filhos de nobres, e, sua preocupação era fazer com que estes falassem. Para León, a possibilidade do surdo falar implicava no seu reconhecimento como cidadão e no seu direito de receber a fortuna e o título familiar, que se não acontecesse colocaria em risco toda a família (MOURA, 2000). 
Em 1750, foi criada a primeira escola pública para surdos por Samuel Heinicke, baseado no método oral. Em 1752, outro professor colaborou na história da educação do surdo, L'epée, que transformou sua casa em uma escola pública para surdos e aprendeu com eles a língua de sinais. Em 1817, foi fundada a primeira escola permanente para surdos nos Estados Unidos da América (EUA), tendo como método de ensino a língua de sinais, utilizada até 1860, quando mudou para o método oral, devido a diversos profissionais acharem que a língua de sinais prejudicava o aprendizado. Em 1868, Roy Holcom adotou, na educação do surdo, a comunicação total que permite qualquer recurso linguístico em momentos diferentes. Outra instituição de ensino que já havia adotado essa metodologia foi à universidade Gallaudet, criada em 1864 nos EUA, tornando-se o maior centro de pesquisa desta filosofia. Historicamente, vemos que a educação de surdos esteve voltada para questóes linguísticas (GOLDFELD, 2002).

No caso do Brasil, a educação de surdos esteve permeada pela discussão do ensino do português (oral e ou escrito) e o uso da língua de sinais (QUADROS, 2004). Em 1857, foi criada a primeira escola para surdos no Rio de Janeiro, o Imperial Instituto dos Surdos-Mudos, que foi um marco para educação de surdos no Brasil. Esta escola contava com apoio da Corte Imperial e os esforços do professor Hernest Huet, trazido pelo imperador Dom Pedro II. No ano de 1957, esta escola recebeu o nome de Instituto de Educação de Surdos (INES), que utilizava, em sua metodologia de ensino, a língua de sinais, que é a língua natural do surdo (STROBEL, 2009).

A educação do surdo no Brasil, antes da vinda do professor Huet, estava associada ao projeto Saquarema, que se constituiu a partir de meados do século XIX, e visava a integração dos povos mais ou menos favorecidos pelo Estado, ao mesmo tempo que revalidava e estabelecia hierarquias e distinçóes (PINTO, 2006). Esta fase da educação do surdo foi marcada por duas vertentes: a médica (que caracteriza a surdez como uma anomalia) e a religiosa (com atos de caridade como cuidados e educaçáo do surdo). Foi após a vinda do professor Huet que o instituto passou a ter o caráter educativo, passando por muitas crises e conquistas. Mesmo com a saída do professor, o instituto recebeu em sua direção pessoas que ajudaram neste processo e no progresso de um grupo especial de alunos que luta até hoje por igualdade e melhores condiçôes de educação (PINTO, 2007).

Em 1994, na cidade de Salamanca (Espanha), na Conferência Mundial de Educação, surgiu a Declaração de Salamanca, um documento de referência mundial e orientador do processo da inclusão (SANCHES; TEODORO, 2006). Após a criaçáo desse documento, a comunidade surda começou a ser vista por um novo ângulo, o que levou a sociedade a uma reflexão sobre sua concepçáo errônea e discriminatória. A Declaração de Salamanca recomendou a implantação de uma nova pedagogia para os alunos surdos, a implantaçáo de programas educacionais direcionados aos surdos, orientação com inclusão e desprendida de qualquer forma de descriminação ou preconceito, contando com professores verdadeiramente capacitados e treinados para executar sua função de despertar o indivíduo para o saber (BRASIL, 1995). 
Tal declaração foi mais além, exigiu do governo uma prioridade política e financeira para o aprimoramento do sistema educacional, para que qualquer indivíduo, independentemente de sua diferença ou dificuldade, pudesse se sentir incluso e dotado de inteligência, perante a sociedade como um todo (CRUZ; DIAS, 2009).

O Ensino Superior no Brasil foi, durante muito tempo, destinado apenas às pessoas com condições econômicas que pudessem manter os altos custos dessa formação, mesmo com o surgimento de universidades públicas. Com o capitalismo industrial e a necessidade de mão de obra qualificada, este quadro mudou, tornando este ensino acessível para as outras classes sociais (MIRANDA; SILVA, 2008).

A educação inclusiva não é algo simplista. É uma questão de direito humano, que necessita de mudanças no seu gerenciamento, e que haja a formação de professores nas metodologias educacionais, com açôes compartilhadas e práticas colaborativas que respondam às necessidades de todos os alunos (SANCHEZ, 2005). De acordo com a Lei n. 9. 394/96 no Art. 2o "educaçâo é dever da família e do Estado. Tem por finalidade o pleno desenvolvimento do educando, seu preparo para o exercício da cidadania e a qualificação para o trabalho" (BRASIL, 2007).

Uma das grandes dificuldades dos alunos surdos no meio acadêmico é de não serem compreendidos tanto pelos ouvintes quanto pelos professores, ou seja, uma barreira comunicacional. A leitura dos textos, devido a diferença na estruturação das línguas envolvidas, também é dificultada, lembrando que a primeira língua do surdo é a de LIBRAS-Língua Brasileira de Sinais e o português é a sua segunda língua (BISOL et al., 2010).

$\mathrm{O}$ aluno surdo entende a necessidade de aprender a língua da maioria, os ouvintes, para uma melhor comunicação, compreensão e entendimento de um determinado conteúdo (CAICA, 2011). Para facilitar a aprendizagem dos alunos surdos, o uso de imagens pode contribuir neste processo devido à necessidade visual que estes já apresentam (JACINTO et al., 2012).

O despreparo dos professores, a respeito das especificidades linguísticas dos surdos, é uma realidade nas instituiçóes de ensino de nível fundamental, médio e superior. Muitos professores recebem os alunos surdos com conceitos preconcebidos ou visões equivocadas a respeito da surdez, deixando este aluno excluído na sala de aula e na relação aluno-professor. Esta situação também gera uma angústia no professor, que pode se isentar da responsabilidade de ensinar o surdo, deixando para os intérpretes ou familiares (SILVA; PEREIRA, 2003). Existe uma necessidade de se buscar mecanismos que possam facilitar o processo de inclusão e aprendizado, em construir uma sociedade mais justa e igualitária, que acolha a todos e suas diferenças (SILVA, 2006).

Muitos são os obstáculos que contribuem para ampliar ainda mais este distanciamento, incluindo a falta de recursos disponíveis para a inclusão dos alunos surdos. É importante mencionar que a presença de professores, profissionais especializados e equipamentos que atendam a todas as necessidades educacionais, são fundamentais no processo de aprendizagem de alunos com ou sem deficiência (SENO, 2009). 
Nesse sentindo, torna-se preeminente a necessidade de investimentos na formação e capacitação dos professores da rede regular de ensino, sobretudo no Ensino Superior, criando oportunidades e o reconhecimento da diversidade que permitirão uma melhor interação com os alunos surdos e, consequentemente, melhorar o processo de aprendizagem, estimulando transformaçóes pedagógicas, a fim de que realmente haja a inclusão (GRASSI, 2009).

Esta pesquisa teve como objetivo avaliar o conhecimento dos discentes, docentes e técnicos do curso de Ciências Biológicas a respeito da surdez, a legislação, a aprendizagem, analisar as condições das salas de aula e laboratórios que atendem os discentes do Curso de Ciências Biológicas e o que poderia ser feito caso houvesse a interação com um aluno surdo.

\section{Metodologia}

Para realização desta pesquisa, primeiramente o projeto foi encaminhado ao Comitê de Ética em Pesquisa com Seres Humanos (CEP/UFU) para aprovação das normas éticas exigidas e foi aprovado em 17 de junho de 2011, segundo Análise Final $n^{\circ} .386 / 11$ do Comitê de Ética em Pesquisa para o protocolo registro CEP/ UFU $174 / 11$.

Inicialmente foram feitas entrevistas (Apêndice 1, 2 e 3) com técnicos (representado pela letra $\mathrm{T}$ ), discentes (A) e docentes (P) do Curso de Ciências Biológicas e dos cursos relacionados, os quais foram escolhidos aleatoriamente. As entrevistas foram gravadas em áudio, com prévia autorização dos entrevistados via termo de consentimento livre e esclarecido (Apêndice 6), depois foram transcritas e apagadas.

O número de sujeitos que foram entrevistados levou em consideração a categoria, tamanho da amostra e o erro amostral. Para a categoria docente, os tamanhos das amostras consideradas foram de todos os docentes do Curso de Ciências Biológicas, exceto a orientadora desta pesquisa e docentes de outros cursos que ministram disciplinas no Curso. Para a categoria dos técnicos de laboratórios, foram considerados todos os técnicos do Curso de Ciências Biológicas e ainda os técnicos dos laboratórios de outros cursos, no qual os discentes tiveram aulas práticas. E finalmente para a categoria discentes, foram considerados todos os discentes regularmente matriculados no curso, dos turnos Integral e Noturno, exceto a pesquisadora-discente.

O erro amostral da pesquisa variou-se, para a categoria docente de $20-30 \%$, técnicos de laboratório de $40-50 \%$ e discentes de $10-15 \%$, de acordo com o tamanho da amostra. As informaçóes sobre as aulas dos docentes foram obtidas através de um formulário (Apêndice 5) que avaliou as condições e a acessibilidade, de forma geral.

Os dados obtidos foram analisados qualitativa e quantitativamente. Para as análises estatísticas foi utilizado o software Excel da Microsoft ${ }^{\circ}$. As análises de cada categoria (discentes, docentes e técnicos) foram estudadas separadamente e agrupados em tabelas diferentes com o ponto de vista geral de cada categoria, possibilitando o estabelecimento da visão que cada um tem do aluno surdo. 


\section{Resultados e discussão}

Entre março de 2011 e fevereiro de 2012, participaram das entrevistas 75 discentes e 10 docentes do Curso de Ciências Biológicas UFU- Campus do Pontal e 4 técnicos do Curso de Ciências Biológicas UFU- Campus do Pontal e cursos associados.

Em relação ao contato com pessoas surdas dentro ou fora da universidade, $47 \%$ dos discentes afirmaram terem tido contato e ainda relataram dificuldade de se comunicar com aluno surdo (Tabela 1). Segundo o entrevistado A1 "uma tia surda, para comunicar com ela precisei da ajuda de um primo, pois não compreendia o que ela dizia". O A2 disse: já tive um vizinho surdo, tentava me comunicar, mas era muito dificil não entendia a maioria das vezes o que ele tentava falar. O A34 comentou "na escola, mas nunca conversei com ele". O contato do A57 foi "na escola, mais náo conseguia me comunicar", já do A60 foi "Quando eles vendiam coisas na rua, mas quase não entendia o que tentava me dizer" e o A72 relata que foi "em um trabalho da faculdade que tive que fazer uma entrevista com um aluno surdo".

Tabela1- Resultados da entrevista com os discentes do Curso de Ciências Biológicas da Universidade Federal de Uberlândia - Campus do Pontal em uma possível interaçáo com alunos surdos dentro da instituição no período de 2011 a 2012.

\begin{tabular}{lccc}
\hline Temas & Sim (\%) & Não (\%) & $\begin{array}{c}\text { Não sabem } \\
(\%)\end{array}$ \\
\hline Contato com pessoa surda & $47 \%$ & $53 \%$ & - \\
Dificuldade na adaptação com aluno surdo & $5 \%$ & $95 \%$ & - \\
Dificuldade no aprendizado dos ouvintes & $9 \%$ & $80 \%$ & $11 \%$ \\
Auxiliar um aluno surdo em sala e laboratório & $82 \%$ & $18 \%$ & - \\
Conhecimento sobre surdez & $83 \%$ & $14 \%$ & $3 \%$ \\
Presenciou atitude de preconceito com alunos & $91 \%$ & $9 \%$ & - \\
inclusivos & 0 & $100 \%$ & - \\
Conhecimento de projetos de inclusão na UFU & $100 \%$ & 0 & - \\
Interesse em conhecer mais sobre surdez & & & - \\
\hline
\end{tabular}

Ao questionar sobre as dificuldades encontradas na adaptação dos ouvintes com um aluno surdo na sala de aula, os discentes que relataram que náo haveria dificuldades nem na adaptaçáo tampouco no aprendizado (Tabela 1). Pode-se notar nos relatos, que a questão da comunicação seria uma das maiores dificuldades na interação destes alunos no espaço acadêmico. Nos depoimentos, o A1 disse: receberia bem, só não saberia me comunicar com ele. O A6 relata "Bem, tentaria auxilia-lo na sua entrada na universidade, a única dificuldade seria na hora de comunicar". O A39 afirma "Eu acho que eu teria dificuldade com ele porque isso é uma experiência diferente na minha vida". O A71 afirma "da melhor maneira possivel, e tendo esse contato eu entenderia melhor a realidade desse aluno surdo". Nos relatos percebe-se um desconforto entre os sujeitos ouvintes quando se trata do assunto da comunicação com o sujeito surdo, 
onde sua maior preocupação foi à incompreensão da língua de sinais de entender e ser compreendido. Para Skliar (2006) os ouvintes sentem um desconforto devido a não compreensão de um mundo diverso do seu próprio, onde sua concepção sobre o surdo é de uma cultura do silêncio e escuridão das mentes sem linguagem.

Sobre o aprendizado dos alunos ouvintes com a presença de um aluno surdo, os discentes ressaltaram que poderia haver um desconforto inicial pelo fato da aula ficar mais lenta, mas que seria superado pela oportunidade de estar aprendendo mais sobre a cultura do surdo e sua língua, sendo uma questão de adaptação. Para os discentes, seria preciso que o docente estivesse preparado para lidar com a questáo da diversidade de cultura em sala de aula, e que o planejamento e a metodologia de ensino deveriam atender as necessidades de todos os alunos para que estes não sofressem nenhum dano em seu aprendizado (Tabela 1). Nesta questáo o entrevistado A8 disse: eu acho que acrescentaria, porque a gente aprenderia até um pouco de como lidar com pessoas surdas. O A11 afirma "Não comprometeria o aprendizado do aluno ouvinte, seria tudo uma questão de adaptação". O A61 disse: Acho aprenderiamos mais com eles. O A92 comentou "Bem, sou a favor da inclusão escolar de pessoas surdas desde que houvesse profissionais capacitados e professores preparados para saber lhe dar com a situação". Os entrevistados que disseram que afetaria o aprendizado, afirmaram que a presença do intérprete acabaria desviando a atenção dos alunos ouvintes, causando algum dano em seu próprio aprendizado.

Ao questionar sobre a relação em sala de aula e laboratório, os alunos ouvintes afirmaram que poderiam auxiliar os alunos surdos, por meios de gestos e mímicas e tentariam aprender a língua de sinais, demonstrando assim a vontade de ajudar (Tabela 1). Nas entrevistas os alunos afirmam "o aluno surdo se comunica de várias formas, e são muito espertos" (A27), o A54 disse: Me expressando através de gestos. O A69 afirma "Não sei muito me comunicar com surdos, mais tentaria ajuda-lo de alguma forma, por gestos ou leitura labial". O A85 comenta "Através de gestos e escritas". Alguns desses alunos afirmaram não poder auxiliar, não pelo desinteresse de ajudar, mas por não compreender o surdo e de náo saber sua língua, que se mostra táo complexa. Por essa falta de conhecimento o aluno ouvinte sente medo de ofender o surdo ao oferecer ajuda. Para Lacerda (1998) este receio no convívio com o aluno surdo no mesmo espaço, faz com que este não se sinta apto a auxiliar o aluno surdo, mesmo que suas concepçốes venham seguidas de açóes inclusivas, os entrevistados demostraram uma insegurança ao ter que se adequar em algo desconhecido até então nunca presenciado em sua vida escolar e acadêmica.

Quando questionados em terem vivenciado algum tipo de situação preconceituosa em relação a alunos inclusivos em ambiente escolar, eles relataram que tinham conhecimento de agressão física e psicológica contra alunos inclusivos (Tabela 1). $\mathrm{O}$ entrevistado A11 relatou que "foi com um cadeirante, os alunos começaram a empurrar a cadeira pra lá e pra cá".

Quando questionados sobre o conceito de surdez, os alunos responderam que surdez é uma pessoa que não escuta, que possui baixa audição ou perda total (Tabela 1). O entrevistado A13 relatou "Falta de audição", o A44 disse: Uma deficiência no 
aparelho auditivo, o A29 afirma "Pessoa que não escuta". Segundo Skliar (1999) essa é uma visão de abordagem clínico-terapêutica que mostra a surdez como uma patologia, relacionada com o déficit biológico orelha não funcional, onde o surdo é uma pessoa que não ouve, portanto não fala.

Ao perguntar aos discentes sobre o conhecimento de projetos de inclusão dentro da universidade, os entrevistados relataram não ter conhecimento de nenhum projeto sobre inclusão de alunos surdos (Tabela 1). A partir de tais dados pode-se afirmar o quáo necessário é a criação de projetos e metas para que ocorra a inclusão. Segundo Mantoan (2006) as medidas tomadas para incluir estes alunos na rede de ensino não estão na direção certa, seja por falta de políticas públicas, ignorância dos pais ou pelo comodismo dos professores. Falta a vontade de mudar essa situação, para que a inclusão aconteça e necessário inovar com soluçôes simples, que precisa ser aceita e compreendida por todos.

Ao serem questionados sobre se conheceriam mais sobre a surdez, os alunos entrevistados afirmaram que se sentiriam interessados pela necessidade na profissão e pela disponibilidade de cursos na universidade (Tabela 1). Nos relatos os discentes afirmam que: A68 "A carreira de docente", A34 "Em fazer a disciplina de Libras", A23 "Através de palestras na universidade", A90 "Na necessidade em conviver com alguém surdo", A41 "Na participação de projetos dentro da universidade". Segundo Vitaliano (2007) para a melhor capacitação e entendimento das pessoas sobre a surdez as universidades deveriam desenvolver, em seus cursos de graduação, pós-graduação e em programas de formação continuada uma preparaçáo para os professores e profissionais da educação atuar frente à diversidade. O que já e garantido pela Lei ${ }^{0} 10.436$, de 24 de abril de 2002, onde todos os cursos de licenciatura, nas diferentes áreas do conhecimento devem fornecer a Libras como disciplina curricular.

Em relação aos professores, quando questionados sobre o contato com alunos surdos em sala de aula, todos afirmaram não terem tido experiência com alunos surdos (Tabela 2). O entrevistado D2 diz: "Já tive contado na universidade que frequentei, mas não estive no mesmo espaço em sala de aula e nunca tive um aluno surdo", o entrevistado D4 comenta "Já tive contato fora do espaço acadêmico, mas nunca trabalhei com um aluno surdo".

Tabela 2 - Resultados da entrevista com os professores do curso de Ciências Biológicas da Universidade Federal de Uberlândia-Campus do Pontal em uma possível interação com alunos surdos dentro da instituição no período de 2011.

\begin{tabular}{lcc}
\hline Temas & Sim (\%) & Não (\%) \\
\hline Contato com aluno surdo em sala de aula & - & $100 \%$ \\
Dificuldade na adaptação com aluno surdo & $100 \%$ & - \\
Interesse em conhecer mais sobre surdez & $100 \%$ & - \\
Conhecimento de projetos de inclusão na UFU & $25 \%$ & $75 \%$ \\
Incentivo da instituição para capacitação na educação de surdos & $100 \%$ & - \\
\hline
\end{tabular}


Sobre as dificuldades na adaptação com alunos surdos, eles ressaltaram não estarem preparados profissionalmente para ensiná-los, devido à falta de conhecimento em Libras e na legislação da educação de surdos (Tabela 2), o entrevistado D6 diz: "Não tive em minha formaçâo acadêmica, informaçôes de como receber estes alunos em sala de aula", de acordo com D10 "Seria necessário presença de um intérprete para auxiliar nas aulas, já que não tive formaçâo sobre Libras".

O Brasil segundo a Organização das Nações Unidas (ONU), foi considerado o país que dispunha da legislação mais avançada para pessoas com deficiência, no entanto, esta legislação não garantiu o total cumprimento destas leis devido às lacunas existentes nestes documentos (BRASIL, 2007). Para Mantoan (2006), essa evasão dos alunos surdos ocorre pelas privaçóes constantes e pela baixa auto-estima resultante da exclusão escolar e social, onde os alunos com deficiência se tornam vítimas das soluçóes sugeridas para reversão desse quadro, que parecem reprisar as mesmas medidas que o criaram, resultando em nenhum avanço importante.

Para conhecer mais sobre a surdez os professores disseram que se sentiriam mais interessados se houvesse um aumento na demanda dos alunos surdos ou por uma necessidade na vida pessoal (Tabela 2). O entrevistado D2 disse: Tenho curiosidade em aprender mais sobre a surdez, já o entrevistado D6 disse: Com a necessidade do aumento da demanda de alunos surdos, o D9 comenta "Com a presença de um aluno na minha sala de aula ou até mesmo na minha vida pessoal".

A maior parte dos professores ainda desconhecem projetos de inclusão dentro da instituição e o único projeto citado pelos professores que afirmaram conhecer foi de um curso preparatório (Tabela 2), como relata o entrevistado D13 disse: Conheço um cursinho preparatório no Campus da cidade de Uberlândia. Para Miranda e Silva (2008), no Brasil a universalização e a democratização do ensino superior ainda é um projeto em desenvolvimento, que necessita de uma grande evolução para se tornar eficiente para alunos com deficiência.

Ao serem perguntados se recebiam algum incentivo da instituição para capacitação na educação de surdos, os entrevistados responderam não receber nenhum tipo de incentivo dentro da universidade, relatando que se houvesse a necessidade de aprender o incentivo partiria deles mesmos (Tabela 2). Segundo o D4 "Não recebo incentivo, mas me auto incentivo se houvesse necessidade", o entrevistado D7 diz: "Nunca recebi incentivo da universidade". Torna-se necessário e urgente um programa de formação para os professores, tanto na carreira quanto na sua graduaçáo, assim, estes se encontrem aptos a incluir tais alunos. Para mudar é necessário conhecer e estar preparados para tal acontecimento (VITALIANO, 2007). 
Tabela 3 - Resultados da entrevista com os técnicos do curso de Ciências Biológicas, Química e Física da Universidade Federal de Uberlândia-Campus do Pontal em uma possível interação com alunos surdos dentro da instituição no período de 2011.

\begin{tabular}{lcc}
\hline Temas & Sim (\%) & Não (\%) \\
\hline Contato com aluno surdo em laboratório & - & $100 \%$ \\
Dificuldade na adaptação com aluno surdo & $25 \%$ & $75 \%$ \\
Incentivo da instituição e capacitação para trabalhar com alunos & - & $100 \%$ \\
surdos & - & $100 \%$ \\
\hline Conhecimento de projetos de inclusão na UFU &
\end{tabular}

$\mathrm{Na}$ entrevista com os técnicos (Tabela 3), eles afirmaram que não tiveram contato com alunos surdos, enquanto técnicos no laboratório. Segundo entrevistado T2 relatou "Nunca auxiliei um aluno surdo no laboratório". Sobre a dificuldade na adaptação com aluno surdo a maior parte dos técnicos relataram não se sentirem aptos a auxiliá-los nas atividades dos laboratórios, devido falta de preparo e desconhecimento de sua língua. Os que responderam não achar que teria dificuldade na adaptação, disseram tentar a ajudar os alunos da melhor maneira possível. Segundo o entrevistado T3 "Não saberia como me comunicar com aluno, mas tentaria ao máximo auxilia-lo através dos roteiros".

Ao serem questionados se a instituição incentivava e capacitava para trabalhar com tais alunos, os entrevistados relataram não terem sido incentivados na realização desses cursos dentro da universidade e que o conhecimento sobre surdez ocorre fora do âmbito acadêmico. O entrevistado T2 diz: não recebi nenhum incentivo da instituição, o T1 "Não da universidade, mas já tenho conhecimento sobre surdez".

Ao perguntar sobre conhecimento de projetos dentro da universidade, todos relataram não conhecer nenhum projeto ou pesquisa que levasse a algum conhecimento sobre educação de surdos. O entrevistado T3 diz "Não conheço dentro da universidade nenhuma pesquisa sobre o assunto". T4 diz: "Não, não conheço nenhum projeto".

Ao analisar os relatos dos entrevistados, nota-se a dificuldade na comunicação de alunos ouvintes e profissionais da educação com pessoas surdas, ocasionado pela falta de convívio/interação e de conhecimento sobre a cultura dos surdos em especial a sua língua a LIBRAS. Para Silva (2003) o uso da Língua de sinais, em sala de aula, contribui na construçáo do conhecimento do aluno surdo, assim com o uso da língua se torna possível essa interação.

Sobre as aulas teóricas, o tom de voz dos professores foi médio e confortável para os alunos, durante as aulas ministradas. Eles utilizam recursos multimídia, como datashow, que são meios facilitadores, para que se possa trabalhar o uso de imagens, vídeos entre outros. O uso desses recursos segundo Nery e Batista (2004) contribui para o acontecimento de [...] diálogos extensos, abordando elementos descritivos e estabelecendo relaçóes e inferências entre os assuntos propostos. Contribuindo assim, no processo educacional do aluno surdo. 
É importante que o professor desenvolva estratégias pedagógicas que visem colaborar no processo de aprendizagem dos alunos surdos, através de metodologias que contribuam em despertar o interesse do aluno surdo, levando em consideração as necessidades deste aluno em sala de aula (RIJO, 2009).

Nos laboratórios, a posição das bancadas pode ser considerada desconfortável, pois dificultou a visão do quadro e do professor. Esta posição possivelmente poderia dificultar o processo de aprendizado do aluno surdo que precisa ter uma visão do professor, sem desviar sua atenção do experimento. Nos laboratório não houve informação visual como ilustraçôes nos equipamentos e vidrarias com sinais específicos em Libras, o que se torna uma dificuldade nas aulas de laboratório (LINDINO, 2011).

As análises revelaram aspectos importantes sobre o cotidiano dos discentes da Universidade e de seus docentes e técnicos, considerando assim que estes apresentaram grandes dificuldades para descrever o impacto da interação com um aluno surdo em sala de aula, uma vez que não é ofertado a estes profissionais o treinamento adequado para trabalhar com alunos surdos. Estas dificuldades e limitaçôes encontradas na educação de surdo trazem inquietaçôes quando se trata de incluir um aluno surdo. A pouca convivência e conhecimento com o surdo torna essa interação uma novidade na universidade, sendo necessária uma mudança da maioria (ouvinte) sobre suas definiçôes em relação à surdez e a identidade surda (LACERDA, 1998).

\section{Considerações finais}

A comunidade acadêmica esta aberta à interação com o aluno surdo, apesar da escassa convivência e das dificuldades iniciais, todos tem a conscientizaçáo da necessidade de aprender mais sobre a surdez. Ao buscar uma soluçáo para receber o aluno surdo na Universidade, constata-se que a maior dificuldade náo está apenas na mobilidade e acessibilidade deste aluno no espaço acadêmico, mas também na forma de encarar algo novo fora dos padróes de "normalidade" para os ouvintes. A visão da dificuldade que se encontra no ensino destes alunos não esta na aprendizagem dos alunos surdos, mas sim, na forma como esse ensino chega até eles. Faz-se necessária uma mudança nas politicas públicas educacionais, nos projetos pedagógicos de formação de professores e, principalmente, na concepção das pessoas de homem e de mundo. Assim, se torna evidente a necessidade das pessoas com deficiência terem seus direitos garantidos, através de trabalhos contínuos de grupos e instituiçóes vinculadas com a inclusão, da capacitaçáo de profissionais de todas as áreas, de projetos que ampliem o atendimento dessas pessoas e na divulgação dos seus direitos, favorecendo a luta a favor da inclusão social e educacional.

\section{Referências}

BISOL, C.A. et al. Estudante Surdos no Ensino Superior: Reflexão sobre a inclusão. Cadernos de Pesquisa, São Paulo, v. 40, n. 139, p. 147-172, 2010. Disponível em: <http://www.scielo.br/pdf/cp/v40n139/v40n139a08. pdf >. Acesso em: 18 mar. 2013.

BRASIL. Declaração de Salamanca de princípios, política e prática para as necessidades educativas especiais. Revista Brasileira Educaçáo Especial, Marília, v. 2, n. 3, p. 141-144, 1995. Disponível em: <http://educa.fcc.org. br/pdf/rbee/v02n03/v02n03a16.pdf>. Acesso em: 08 jun. 2013. 
BRASIL. Lei no 9394, de 20 de dezembro de 1996. Estabelece as Diretrizes e Bases da Educação Nacional. Diário Oficial da Uniăo, de 23 de dezembro de 1996. Disponível em: <http://www.planalto.gov.br/ccivil_03/_ Ato2011-2014/2013/Lei/L12796.htm\#art1>. Acesso em: 7 Ago. 2013.

Presidência da República; Secretaria Especial dos Direitos Humanos. Coordenadoria Nacional para Integraçáo da Pessoa Portadora de Deficiência. Convençáo sobre os Direitos das Pessoas com Deficiência: Protocolo Facultativo à Convenção sobre os Direitos das Pessoas com Deficiência. Brasília: CORDE, 2007. Disponível em: <http://www.governoeletronico.gov.br/biblioteca/arquivos/a-convencao-sobre-os-direitos-das -pessoas-com-deficiencia-comentada>. Acesso em: 15 Ago. 2013.

BOTELHO, P. Segredos e Silêncios na Interpretaçáo dos Surdos. Belo Horizonte: Autêntica, 1998.

CAICA, O. L. A. Teacher: Can You See What I'm Saying? A Research Experience with Deaf Learners. Profile, Bogotá, v. 13, n. 2, p. 130-146, 2011. Disponível em: <http://www.scielo.org.co/scielo.php?script=sci_arttext\&pid=S1657-07902011000200010\&lang=pt>. Acesso em: 19 mar. 2013.

CRUZ, J. I. G.; DIAS, T. R. S. Trajetória escolar do surdo no Ensino Superior: condiçōes e possibilidades. Rev. Bras. Ed. Esp., Marília, v. 15, n. 1, p. 65-80, 2009. Disponível em: <http://www.scielo.br/scielo.php?pi$\mathrm{d}=$ S1413-65382009000100006\&script=sci_abstract\&tlng=pt $>$. Acesso em: 18 mar. 2013.

GOLDFELD, M. A criança surda: linguagem e cognoção numa perspectiva sócio-interacionista. 2 ed. São Paulo: Plexus, 2002.

GRASSI, D. A inclusão de surdos na Universidade - um estudo de caso. 2009. Trabalho de Conclusão de Curso. (Especialização) - Curso de Especialização em Educação Profissional Tecnológica Inclusiva, Centro Federal de Educaçẫo Tecnológica, Cuiabá, 2009. Disponível em: <http://bento.ifrs.edu.br/site/midias/arquivos/201007111045971dayse_grassi.pdf>. Acesso em: 17 fev. 2013.

JACINTO, L. A. et al. Visual stimuli and written production of deaf signers. J. Soc. Bras. Fonoaudiol., v. 24, n. 2, p. 193-197, 2012. Disponível em: <http://www.scielo.br/scielo.php?script=sci_arttext\&pi$\mathrm{d}=$ S2179-64912012000200018\&lang=pt $>$. Acesso em: 19 mar. 2013.

LACERDA, C. B. F. Um pouco da história das diferentes abordagens na educação dos surdos. Cad. CEDES. Campinas, v. 19, n. 46, p. 68-80, 1998. Disponível em: <http://www.scielo.br/scielo.php?script=sci_arttext\&pid=S0101-32621998000300007\&lng=pt\&nrm=iso $>$ Acesso em: 03 fev. 2013.

LINDINO, C. A. et al. Química para surdo: um relato de experiência. Revista Trama. Toledo, v. 7, n. 14, p. 11-22, 2011.

MANTOAN, M. T. E. Inclusáo escolar: O que é? Por quê? Como fazer? 2 ed. São Paulo: Moderna, 2006.

MIRANDA, A. A. B.; SILVA, L. C. Um olhar sobre a realidade das pessoas com deficiência no contexto universitário. In: DECHICHI, C.; SILVA, L.C. (Orgs.). Inclusáo escolar e educaçáo especial: teoria e prática na diversidade. Uberlândia: EDUFU, 2008. p. 119-149

MOURA, M. C. O surdo: caminhos para uma nova identidade. 1 ed. Rio de Janeiro: Revinter, 2000.

NERY, C. A.; BATISTA, C. G. Imagens visuais como recursos pedagógicos na educaçâo de uma adolescente surda: um estudo de caso. Paidéia, Ribeirão Preto, v. 14, n. 29, p. 287-299, 2004. Disponível em: <http://www. scielo.br/scielo.php?script=sci_arttext\&pid=S0103-863X2004000300005>. Acesso em: 8 ago. 2013.

PINTO, F. B. O silencioso despertar do mundo surdo brasileiro. Revista de História e Estudos Culturais. Rio de Janeiro, v. 3, n. 2, p. 1-14, 2006. Disponível em: <http://www.revistafenix.pro.br/PDF7/03\%20ARTIGO\%20FERNANDAPINTO.pdf> Acesso em: 19 mar. 2013.

Vendo vozes: a história da educação dos surdos no Brasil oitocentista. 2007. Disponível em: <http:// www.cultura-sorda.eu/resources/Bouth_vendo_vozes.pdf>. Acesso em: 25 nov. 2010

QUADROS, R. M. Educação de surdos: efeitos de modalidade e práticas pedagógicas. In: MENDES, E. G.; ALMEIDA, M. A.; WILLIAMS, L. C. A. (Orgs.). Temas em educaçáo especial IV. São Carlos: EDUFSCAR, 2004, p. 55-61.

RIJO, M. G. Q. A inclusão de alunos surdos nas escolas públicas de Passo Fundo. 2009. Trabalho de Conclusão de Curso. (Pós-graduação) - Curso de Especialização em "Educação Profissional e Tecnológica Inclusiva", Instituto Federal do Mato Grosso, Mato Grosso, 2009.

SANCHES, I.; TEODORO, A. Da integração à inclusão escolar: cruzando perspectivas e conceitos. Lusófona de Educaçào, Lisboa, n. 8, p. 63-83, 2006. Disponível em: <http://www.scielo.oces.mctes.pt/pdf/rle/n8/n8a05. pdf>. Acesso em: 8 ago. 2013. 
SÁNCHEZ, P. A. A educação inclusiva: um meio de construir escolas para todos no século XXI. Inclusão Revista de Educaçáo Especial, Brasília, v. 1, n. 1, p. 7-18, 2005. Disponível em: <http://portal.mec.gov.br/ seesp/arquivos/pdf/revistainclusao1.pdf>. Acesso em: 7 jul. 2013.

SENO, M. P. A inclusão do aluno com perda auditiva na rede municipal de ensino da cidade de Marília. Revista Psicopedagogia. São Paulo, v.26, n. 81, p. 376-387, 2009. Disponível em: <http://pepsic.bvsalud.org/scielo. php?pid=S0103-84862009000300005\&script=sci_arttext>. Acesso em: 18 mar. 2013.

SILVA, A. B. P.; PEREIRA, M. C. C. O aluno surdo na escola regular: imagem e ação do professor. Psicologia: Teoria e Pesquisa. Brasília, v. 19, n. 2, p. 173-176, 2003. Disponível em: <http://www.scielo.br/scielo.php?pi$\mathrm{d}=$ S0102-37722003000200010\&script=sci_arttext $>$. Acesso em: 20 mar. 2013.

SILVA, C. M. D. Inclusão: dos limites às possibilidades. In: ROTH, B.W. (Org.). Experiências educacionais inclusivas: Programa Educação Inclusiva: direito à diversidade. Brasília: Ministério da Educação, Secretaria de Educaçáo Especial, 2006, p. 121-130. Disponível em: <http://portal.mec.gov.br/seesp/arquivos/pdf/experienciaseducacionaisinclusivas.pdf>. Acesso em: 10 jun. 2013.

SKLIAR, C. (Org.). Atualidade da educaçáo bilíngue para surdos. 2. Ed. Porto Alegre: Mediação, 1999.

(Org.). Educaçáo e exclusáo: abordagens sócio-antropológicas em educação especial. 5. ed. Porto Alegre: Mediação, 2006.

STROBEL, K. História da Educaçáo de Surdos. Florianópolis, 2009. Disponível em: <http://www.libras. ufsc.br/colecaoLetrasLibras/eixoFormacaoEspecifica/historiaDaEducacaoDeSurdos/assets/258/TextoBase_HistoriaEducacaoSurdos.pdf>. Acesso em: 18 mar. 2013.

VITALIANO,C. R. Análise da necessidade de preparação pedagógica de professores de cursos de licenciatura para inclusão de alunos com necessidades educacionais especiais. Rev. Bras. Ed. Esp., Marília, v. 13, n. 3, p. 399-414, 2007. Disponível em: <http://www.scielo.br/pdf/rbee/v13n3/a07v13n3.pdf>. Acesso em: 18 mar. 2013.

\section{Correspondência}

Tatiane Aparecida Silva - Avenida Doutor Munir Tannús Abdalla, n. 201, Bloco 24, Apto. 103, Shopping Park, CEP: 38411-449, Uberlândia - Minas Gerais - Brasil.

E-mail: tatiane.asn@hotmail.com - luizantonio.s@hotmail.com - vanessa.kataguiri@ufu.br - deicy_ufu@hotmail.com

Recebido em 17 de agosto de 2015

Aprovado em 06 de abril de 2016 
